\title{
Low arterial oxygen partial pressure induces pulmonary thrombocytopenia in patients and a mouse model
}

Limeng Wu ${ }^{1 \dagger}$, Ninghong Guo ${ }^{1,2 \dagger}$, Zhenyan Xu ${ }^{3}$, Wei Wang ${ }^{4}$, Qinmei Xiong ${ }^{1}$, Jinzhu Hu ${ }^{1}$, Rong Wan ${ }^{3}$ and Kui Hong ${ }^{1,3,5^{*}}$ (1)

\begin{abstract}
Background: Recent basic studies demonstrate that the lung is a primary organ of platelet biogenesis. However, whether the pathophysiological state of the lung affect the platelets is little known. We aim to investigate the incidence of thrombocytopenia in patients with pulmonary infection (PIN) and risk factors associated with pulmonary thrombocytopenia.
\end{abstract}

Methods: In total, 11,941 patients with pulmonary infection (PIN) were enrolled, and patients with other three infectious diseases were collected as controls. The incidence of thrombocytopenia was compared, and the risk factors associated with thrombocytopenia in PIN patients were investigated by multivariate analysis. To explore the mechanism of thrombocytopenia, hypoxic model was constructed. Blood platelet counts from the angular vein (PLTs), left ventricle ( $\mathrm{PLT}_{\text {post }}$ ) and right ventricle ( $\mathrm{PLT}$ pre were determined. Megakaryocytes identified by anti-CD41 antibody were detected through flow cytometry and immunofluorescence.

Results: The incidence of thrombocytopenia in PIN was higher than that in other three infectious diseases ( $9.8 \%$ vs. $6.4 \% \sim 5.0 \%, P<0.001)$. Low arterial oxygen partial pressure $\left(\mathrm{PaO}_{2}\right)$ was an important risk factor for thrombocytopenia $(\mathrm{OR}=0.88 ; P<0.001)$. In a hypoxic mouse model, PLTs decreased $(518.38 \pm 127.92$ vs $840.75 \pm 77.30, P<0.05)$, which showed that low $\mathrm{PaO}_{2}$ induced thrombocytopenia. The difference between the $\mathrm{PLT}_{\text {post }}$ and $\mathrm{PLT}$ pre $(\triangle \mathrm{PLT}$ post-pre), representing the production of platelets in the lungs, was significantly attenuated in hypoxic mice when compared with normoxic mice ( $F=25.47, P<0.05)$. Additionally, proportions of CD41-positive megakaryocytes in the lungs, marrow, spleen all decreased in hypoxic mice.

Conclusion: There is a high incidence for thrombocytopenia in PIN patients. Low $\mathrm{PaO}_{2}$-induced thrombocytopenia is associated with impaired generation of platelet in the lungs.

Keywords: Pulmonary infection, Thrombocytopenia, Lung, Platelet, Oxygen partial pressure

*Correspondence: hongkui88@163.com

${ }^{\dagger}$ Limeng Wu and Ninghong Guo Co-first author

tThese authors contributed equally to this work

${ }^{1}$ Department of Cardiovascular Medicine and Jiangxi Key Laboratory

of Molecular Medicine, The Second Affiliated Hospital of Nanchang

University, Nanchang 330006, Jiangxi, China

Full list of author information is available at the end of the article

\section{Background}

Platelets are critical for hemostasis and thrombosis [1]. It is a classic view that megakaryocytes (MKs) produce platelets in the bone marrow. Interestingly, several studies have shown that a large mass of MKs exist in lungs, which indicates that the lungs may be a specific organ for platelet biogenesis [2-4]. The latest discovery strongly indicated that a large number of MKs circulated through 
the lungs, where they dynamically released platelets, and an animal model showed that the lungs contributed approximately $50 \%$ of total platelet production in mice [3]. It is often observed that thrombocytopenia appears in patients with pulmonary diseases, such as pneumonia, chronic obstructive pulmonary disease (COPD) or respiratory failure (RF), which leads to major bleeding events and death [4-7]. However, whether pathophysiological state of lung affects platelets is unclear from both clinical and basic research information. The present study, firstly, aims to explore whether the risk of thrombocytopenia varies among different organ infection, and we found that the incidence of thrombocytopenia in pulmonary infection (PIN) was the highest and low oxygen partial pressure $\left(\mathrm{PaO}_{2}\right)$ was a key risk factor for thrombocytopenia in PIN. Secondly, mice hypoxia model were used to uncover the potential mechanism of thrombocytopenia associated with the lung.

\section{Methods}

\section{Subjects}

Data were obtained from the large data center of the Second Affiliated Hospital of Nanchang University from January 1,2014 , to June 30,2018 . International classification of diseases code-10 (ICD-10) was applied to identify the diagnosis of PIN [8]. Additionally, patients with urinary tract infection (UTI), intestinal tract infection (ITI) or skin soft-tissue infection (SSI) were collected as controls to distinguish PIN-specific effects of infection. All subjects meeting any of the following criteria were excluded: (1) younger than 18 years old; (2) pregnant or lactating; (3) presence of infection at two or more sites; (4) a total bilirubin, alanine aminotransferase or aspartate aminotransferase level 1.5 times higher than the normal value or a serum creatinine level 1.2 times higher than the normal value [9]; (5) presence of any disorder that could lead to thrombocytopenia, including hematopoietic disease, cancer, hepatitis, cirrhosis, hypersplenism, autoimmune disease, disseminated intravascular coagulation and hemorrhagic fever; and (6) concomitant intake of medication that could affect the platelet, including chemotherapeutic drugs, monoclonal antibodies, antiplatelet drugs, anticoagulant drugs, and some antibiotics (e.g. linezolid and vancomycin). The clinical pulmonary infection score (CPIS), which is used to assess the severity of PIN [10] and the Acute Physiology And Chronic Health Evaluation II (APACHE II) score, which is used to estimate the severity of RF [11], were calculated with data collected by a third person blinded to the experimental design to avoid bias. Thrombocytopenia was defined as a platelet count lower than $100 \times 10^{9} / \mathrm{L}$, which was defined according to the corresponding statement by the World Health Organization [12]. All procedures were approved by the Medical Ethics Committee of the Second Affiliated Hospital of Nanchang University.

\section{Mouse models}

Sixteen C57BL/6 male mice (20-28 g, age 10 weeks) were purchased from Laboratory Animal Science Department of Nanchang University. To verify whether the $\mathrm{PaO}_{2}$ is associated with thrombocytopenia, we generated a respiratory failure model in mouse and the protocol was well-accepted and utilized by other researchers [13]. The mice were randomly assigned into two groups. Hypoxic mice $(\mathrm{N}=8)$ were housed in a hypobaric chamber with an $8 \% \mathrm{O}_{2}$ concentration and $58-66 \%$ humidity for 28 continuous days, while control mice $(\mathrm{N}=8)$ were housed in normal air conditions. The mice were kept under conditions with controlled lighting ( $12 \mathrm{~h}$ per day) and temperature $\left(21 \pm 2{ }^{\circ} \mathrm{C}\right)$ and were free to standard laboratory food and water. Four mice were placed in one cage. At the end of 28-day hypoxia treatment, mice were anesthetized by inhaling $5 \%$ isoflurane and blood was obtained quickly, then all mice were euthanized by cervical dislocation and the tissues were collected. In order to ensure the repeatability, experiment were performed on independent days as separate replicates. All procedures were approved by the Animal Care and Use Committee of the Second Affiliated Hospital of Nanchang University.

\section{Platelet counts and P-selectin assessment}

Mice were anesthetized by inhalation of isoflurane(RWD, China) before blood collection. The platelet counts of blood samples collected from different sites including the angular vein (PLTs), the right ventricle $\left(\mathrm{PLT}_{\mathrm{pre}}\right)$ and the left ventricle $\left(\mathrm{PLT}_{\text {post }}\right)$ were determined with an automatic blood cell analyzer(Bio-rad TC20, USA). Plasma soluble P-selectin, a marker of platelet activation, was evaluated by enzyme-linked immunosorbent assay (Invitrogen, USA).

\section{Flow cytometry}

To obtain a single-cell suspension, $100 \mathrm{mg}$ lung was digested with LiberaseTM (Roche, Germany)at a concentration of $26 \mathrm{U} / \mathrm{ml}$ and $5 \%$ DNase I in a $37{ }^{\circ} \mathrm{C}$ warm bath for $30 \mathrm{~min}$, followed by filtration through a $100-\mu \mathrm{m}$ sieve; and cell suspensions of bone marrow and spleen were performed as described previously [14, 15]. Cell suspensions treated with $1 \mathrm{ml} \mathrm{RBC}$ lysis buffer (Solarbio, China) were incubated with anti-CD41 FITC-conjugated antibody (eBioscience, USA) in the dark for $30 \mathrm{~min}$ and then evaluated by flow cytometry [16]. IgG FITC-conjugated isotype control antibody(eBioscience, USA) was applied to gated. 


\section{Tissue immunofluorescence}

Lung, femur and spleen of mice were rapidly removed after euthanasia and fixed with $4 \%$ paraformaldehyde for $24 \mathrm{~h}$. Fixed tissue specimens were dehydrated in ethanol, infiltrated, embedded into paraffin. For an individual mouse, 5 sections were randomly cut along the direction of the maximum section of the tissue. Sections (2-mm thick) were incubated with anti-CD41 primary antibody (Proteintech, USA) in PBS containing 1\% BSA overnight at $4{ }^{\circ} \mathrm{C}$ [17], followed by secondary antibody conjugated to Alexa Fluor 488 or 568 (Invitrogen Corporation, Molecular Probes) for $1 \mathrm{~h}$ at room temperature. Finally, the slide was observed by a fluorescence microscope(OLYMPUS, JAPAN) and analyzed by the software(Image-Pro Plus 6.0., CHINA). The number of CD41-positive cells per square millimeter was calculated.

\section{Statistical analysis}

Statistical analysis was performed by using SPSS 13.0 software (SPSS Inc. Chicago, Illinois, USA). Continuous variables are expressed as the mean \pm standard deviation $(x \pm S D)$, while categorical variables are presented as relative frequencies. Logistic regression models were used to identify clinical factors associated with thrombocytopenia. All covariates that reached statistical significance $(P<0.05)$ in univariate analyses were selected for multivariate analysis. An independent $t$ test was used for comparisons between two groups if the data conformed to a normal distribution. Otherwise, the Mann-Whitney $\mathrm{U}$ test was used. A paired $t$-test was used to compare

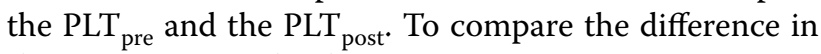
the $\triangle \mathrm{PLT}_{\text {post-pre }}$ value between two groups, a covariance analysis model was used. A $P$ value $<0.05$ was considered statistically significant.

\section{Results}

\section{Patient cohort}

A total of 11,941 (70.5\%) patients with PIN were enrolled, while 3327(19.7\%) patients with UTI, 1053 (6.2\%) patients with ITI, and $602(3.6 \%)$ patients with SSI were collected to be used as controls. The initial cohort included 16,923 patients (Fig. 1), and the baseline characteristics are presented in Table 1 . The incidence of thrombocytopenia were $9.8 \%$ (PIN), $6.4 \%$ (UTI), 5.0\% (ITI) and 5.1\% (SSI).

\section{Patients with PIN showed a higher incidence of thrombocytopenia than patients with other infectious diseases}

For all subjects with infectious disease, factors associated with thrombocytopenia by logistic analysis are shown in Table 2. By univariate analysis, sex, hypertension comorbidity and different infection sites were associated with thrombocytopenia. In multivariate analysis, after adjusting for the sex and hypertension comorbidity confounders, patients with other organ infections presented a lower incidence of thrombocytopenia than PIN patients $\operatorname{did}$ (UTI OR $=0.61,95 \%$ CI: $0.52-0.71$; ITI OR $=0.48$, 95\% CI: 0.33-0.69; SSI OR $=0.46,95 \%$ CI: $0.35-0.61$; all $P<0.001$ ), which indicates that patients with PIN are more likely to develop thrombocytopenia than patients with one of three other infections.

\section{PIN patients with RF comorbidity had a relatively high risk for thrombocytopenia}

To explore the risk factors for thrombocytopenia in PIN patients, factors influencing thrombocytopenia were identified by logistic analysis (Table 3 ). The CPIS was evaluated to assess the severity of PIN [10]. Univariate analysis showed that the higher CPIS was $(\mathrm{OR}=1.25$, 95\% CI: $1.18-1.32 ; P<0.001)$, the higher the risk of thrombocytopenia. RF (OR $=1.68,95 \%$ CI: $1.35-2.09$; $P<0.001)$ and hypertension (OR $=0.73$, 95\% CI: $0.65-$ $0.83 ; P<0.001)$ were associated with thrombocytopenia. Multivariate analysis showed that hypertension was a positive factor for thrombocytopenia $(\mathrm{OR}=0.74,95 \% \mathrm{CI}$ : 0.65-0.85; $P<0.001)$. RF (OR $=1.59,95 \%$ CI: $1.27-1.98$; $P<0.001)$ and a high CPIS (OR $=1.24,95 \%$ CI: $1.17-1.31$; $P<0.001)$ were risk factors for thrombocytopenia. Interestingly, patients with RF appeared more prone to thrombocytopenia than those without RF.

\section{Low $\mathrm{PaO}_{2}$ was a key risk factor for thrombocytopenia}

To explore the key effective factor in PIN patients with $\mathrm{RF}$, a subgroup analysis was conducted and the result is shown in Table 4. The APACHE II scoring system was adopted here to estimate the severity of RF [11]. Univariate analysis showed that the higher the APACHE II score was $(\mathrm{OR}=1.09,95 \% \mathrm{CI}: 1.02-1.15 ; P=0.007)$, the higher the risk of thrombocytopenia was. Relatively low $\mathrm{PaO}_{2}(\mathrm{OR}=0.88$, 95\% CI: 0.85-0.91; $P<0.001)$, hypertension $(\mathrm{OR}=0.64,95 \% \mathrm{CI}: 0.41-0.99 ; P=0.046)$ and $\mathrm{COPD}$ $(\mathrm{OR}=2.35,95 \% \mathrm{CI}: 1.22-4.53 ; P=0.01)$ were associated with thrombocytopenia. In multivariate analysis, both COPD $(\mathrm{OR}=2.40,95 \% \mathrm{CI}: 1.22-4.76 ; P=0.01)$ and a high APACHE II score $(\mathrm{OR}=1.06,95 \% \mathrm{CI}$ : $1.01-1.13$; $P=0.03$ ) were risk factors for thrombocytopenia. It was important to emphasize that low $\mathrm{PaO}_{2}$ was a potential risk factor for thrombocytopenia, which was supported by result of relatively high $\mathrm{PaO}_{2}$ associated with a relatively low risk of thrombocytopenia $(\mathrm{OR}=0.88,95 \%$ CI: $0.85-0.92 ; P<0.001)$. There was no difference in the distribution of $\mathrm{PaO} 2$ among different pathogen groups $(P=0.11)$ (Additional file 1: Fig. 1). Likewise, pathogens 


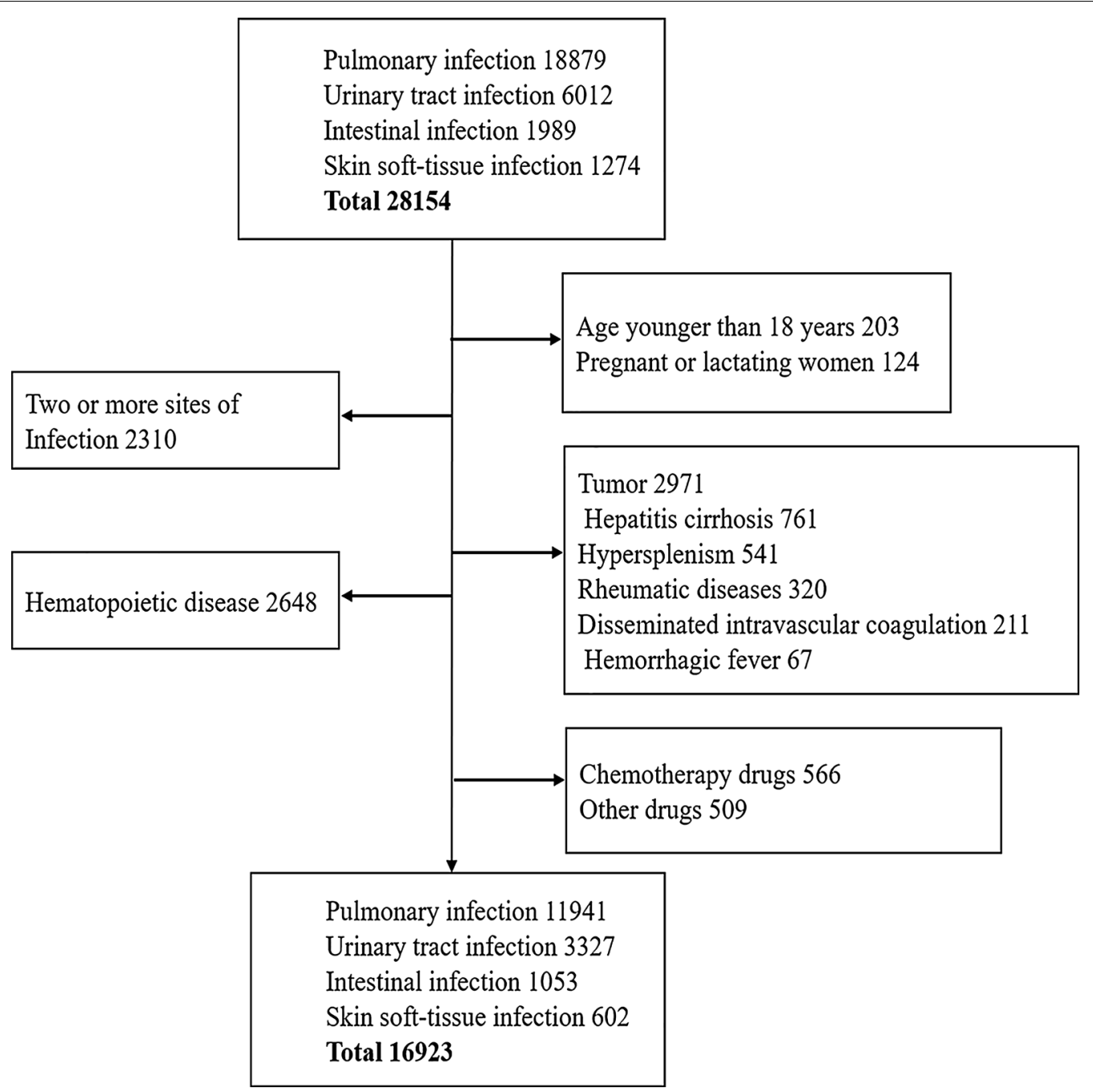

Fig. 1 Flowchart showing the process of this study

weren't associated with thrombocytopenia in PIN patients with RF (all $P>0.05$ ) (Additional file 2: Table 1).

\section{Hypoxic mouse models with low $\mathrm{PaO}_{2}$}

To verify whether low $\mathrm{PaO}_{2}$ is a risk factor for thrombocytopenia, hypoxic mouse models were constructed [13] to analyze the blood gas content in left ventricular blood. The results showed that the $\mathrm{PaO}_{2}(\mathrm{mmHg})$ decreased significantly in blood from hypoxic mice $(n=8)$ compared with that from normoxic mice $(59.63 \pm 6.39 v s$. $76.63 \pm 9.58$, respectively; $P<0.05)$. For each Comparation, the sample size was eight.
Reduction in PLTs independent of platelet activation after hypoxia

The count of PLTs $\left(\times 10^{9} / \mathrm{L}\right)$ in angular vein blood decreased in hypoxic mice compared with that of normoxic mice $(518.38 \pm 127.92$ vs. $840.75 \pm 77.30$, respectively; $P<0.05)$ and accompanied by increased hemoglobin (HGB) level (g/L) (196.0 \pm 10.56 vs. $140.0 \pm 5.78$, respectively; $P<0.05)$. There was no difference in the plasma soluble P-selectin concentration(ng/ $\mathrm{ml})$ between these two groups $(77.55 \pm 5.38$ vs. $74.86 \pm 7.85$, respectively; $P>0.05)$. For each comparation, the sample size was eight.

\section{MK numbers decreased in hematopoietic organs} after hypoxia

To explore the possible reason for thrombocytopenia after hypoxia treatment, we investigated the amount of 
Table 1 Baseline Characteristics of Patients with Infectious Diseases $(N=16,923)$

\begin{tabular}{|c|c|c|c|}
\hline Variables & $\begin{array}{l}\text { Thrombocytopenia } \\
(n=1468)\end{array}$ & $\begin{array}{l}\text { Normal platelet } \\
(n=15,455)\end{array}$ & $p$ Value \\
\hline \multicolumn{4}{|c|}{ Demographic characteristics } \\
\hline Age, years & $57.94 \pm 23.62$ & $58.57 \pm 23.81$ & 0.34 \\
\hline Sex, female, n (\%) & $876(59.7)$ & $8771(56.8)$ & $0.03^{*}$ \\
\hline $\begin{array}{l}\text { Infection location, } \\
\text { n (\%) }\end{array}$ & & & $<0.001^{*}$ \\
\hline Lung & $1171(9.8)$ & $10,770(90.2)$ & \\
\hline Urinary tract & $213(6.4)$ & 3114(93.6) & \\
\hline Intestinal tract & $53(5.0)$ & 1000(95.0) & \\
\hline Skin soft-tissue & $31(5.1)$ & $571(94.9)$ & \\
\hline \multicolumn{4}{|c|}{ Biochemical indexes } \\
\hline WBC $\left({ }^{*} 10^{9} / \mathrm{L}\right)$ & $9.92 \pm 3.99$ & $10.00 \pm 4.09$ & 0.54 \\
\hline $\mathrm{HB}(\mathrm{g} / \mathrm{L})$ & $128.46 \pm 33.44$ & $127.45 \pm 33.42$ & 0.27 \\
\hline $\operatorname{PLT}\left({ }^{*} 10^{9} / \mathrm{L}\right)$ & $70.33 \pm 23.53$ & $211.32 \pm 80.26$ & $<0.001^{*}$ \\
\hline TBil $(\mu \mathrm{mol} / \mathrm{L})$ & $19.94 \pm 8.62$ & $19.81 \pm 8.53$ & 0.58 \\
\hline AST (U/L) & $36.07 \pm 13.60$ & $36.49 \pm 13.66$ & 0.26 \\
\hline ALT $(U / L)$ & $42.17 \pm 18.80$ & $41.84 \pm 19.08$ & 0.54 \\
\hline $\begin{array}{l}\text { Creatinine } \\
(\mathrm{mmol} / \mathrm{l})\end{array}$ & $93.86 \pm 30.21$ & $93.30 \pm 30.18$ & 0.49 \\
\hline CRP (mg/L) & $50.48 \pm 48.53$ & $51.21 \pm 49.21$ & 0.67 \\
\hline PCT (ng/ml) & $0.35 \pm 0.21$ & $0.25 \pm 0.35$ & 0.60 \\
\hline \multicolumn{4}{|c|}{ Medical history, $n(\%)$} \\
\hline Hypertension & $453(30.9)$ & $5512(35.7)$ & $<0.001^{*}$ \\
\hline Diabetes & $220(15.0)$ & $2613(16.9)$ & 0.06 \\
\hline
\end{tabular}

Date were presented as mean $\pm(\mathrm{SD})$ or $\mathrm{n}(\%)$. The physiological variables were collected within the first $24 \mathrm{~h}$ of admission. "Significant differences $(P<0.05)$ WBC white blood cell, HB haemoglobin, PLT platelet, TBil total bilirubin, AST aspertate aminotransferase, $A L T$ alanine aminotransferase, CRP C-reactive protein, $P C T$ procalcitonin

megakaryocytes in hematopoietic organs including lung, marrow and spleen. The results of flow cytometry analysis showed lower proportions of CD41-positive cells (\%) in lungs (6.09 [5.66-6.71] vs. 8.82 [8.26-10.27], respectively; $P<0.05$, Fig. $2 \mathrm{a}, \mathrm{b})$, bone marrow $(2.11 \pm 1.12$ vs. $5.03 \pm 1.72$, respectively; $P<0.05$, Fig. 2 c,d) and spleen (0.39 [0.36-0.59] vs. 0.74 [0.66-1.03], respectively; $P<0.05$, Fig. $2 \mathrm{e}-\mathrm{f})$ in hypoxic mice than in normoxic mice. Consistent with the flow cytometry results, the counts of CD41-positive cells calculated by fluorescence microscopy in lungs ( $39.0 \pm 5.35$ vs. $54.25 \pm 12.87$, respectively; $P<0.05$, Fig. 3a,b), bone marrow $(10.00 \pm 2.78$ vs. $24.88 \pm 3.68$, respectively; $P<0.05$, Additional file 3 : Fig. $2 \mathrm{~A}-\mathrm{B})$ and spleen $(2.75 \pm 1.04$ vs. $8.75 \pm 5.29$, respectively; $P<0.05$, Additional file 4 : Fig. $3 \mathrm{~A}-\mathrm{B}$ ) in hypoxic mice were lower than those in normoxic mice. These results suggested that the reduction of megakaryocytes in the three hematopoietic organs after hypoxia might be part of the reason for thrombocytopenia. We speculate a perturbed PLT production in lung with the effect of hypoxia.

\section{Impaired platelet production was observed in hypoxic mouse lungs}

To determine the number of platelets produced in lungs, we investigated the PLT $\mathrm{Pre}_{\text {pre }}$ and the PLT ${ }_{\text {post }}$. The result showed thatthe PLT post $_{\text {was }}$ higher than the PLT $_{\text {pre }}$ in the normoxic group $(713.63 \pm 124.15$ vs. $543.75 \pm 121.17$, respectively; $P<0.05)$, which indicated that thrombopoiesis occured in lungs. However, this phenomenon was not obvious in hypoxic mice $(339.63 \pm 95.47$ vs. $391.13 \pm 117.30$, respectively; $P>0.05$ ). Namely, the $\triangle \mathrm{PLT}_{\text {post-pre }}$ value was less significant in the hypoxic group than in the normoxic group $(\mathrm{F}=25.47, P<0.05)$. For each Comparation, the sample size was eight.

\section{Discussion}

There have been some cases of thrombocytopenia in PIN patients, but observational study of large samples is rare. We performed a retrospective study to observe the incidence of thrombocytopenia in patients with PIN, and patients with one of three other kinds of infections which was the most common in our hospital were chosen as controls. The results showed that the highest incidence of thrombocytopenia occurred in PIN patients among the four groups of infectious disease patients, suggesting that thrombocytopenia was likely associated with pulmonary infection. Subgroup analysis showed that PIN patients with RF had a higher risk of thrombocytopenia than those without RF. Furthermore, PIN with RF patients showing low $\mathrm{PaO}_{2}$ were more likely to have thrombocytopenia. These results indicated that low $\mathrm{PaO}_{2}$ might be a key risk factor for thrombocytopenia. In view of studies showing that the lungs can produce platelets $[18,19]$, it was reasonable to speculate that low $\mathrm{PaO}_{2}$ might induce thrombocytopenia by impairing platelet production in lungs. To verify our hypothesis, we built a hypoxic mouse model, and the results showed that PLTs were decreased in hypoxic mice compared with normoxic mice, which demonstrated that low $\mathrm{PaO}_{2}$ indeed induced thrombocytopenia. In keeping with the fact that MKs circulate through the pulmonary capillaries where they release platelets[19], the PLT ${ }_{\text {post }}$ representing the postpulmonary(left ventricle) blood platelet, was increased compared with the PLT $\mathrm{Pre}_{\text {indicating the }}$ prepulmonary(right ventricle) blood platelet in normoxic mice. Hence, the $\triangle P L T$ post-pre index represented the generation of platelets in lungs $[20,21]$. Our results showed that $\triangle \mathrm{PLT}_{\text {post-pre }}$ was significantly attenuated in hypoxic mice compared with normoxic mice. The lower proportion of CD41-positive MKs indicated by histology and flow cytometry, and the decreased $\triangle \mathrm{PLT}_{\text {post-pre }}$ in 
Table 2 Comparison of the incidence of thrombocytopenia between patients with pulmonary infection and other infections

\begin{tabular}{|c|c|c|c|c|c|c|}
\hline \multirow[t]{2}{*}{ Variables } & \multicolumn{3}{|c|}{ Univariate analysis } & \multicolumn{3}{|c|}{ Multivariate analysis } \\
\hline & OR & $95 \% \mathrm{Cl}$ & $P$ value & $\overline{O R}$ & $95 \% \mathrm{Cl}$ & $P$ value \\
\hline Age, years & 0.99 & $0.99-1.00$ & 0.33 & & & \\
\hline Sex, females & 1.13 & $1.01-1.26$ & $0.03^{*}$ & 1.09 & $0.98-1.22$ & 0.14 \\
\hline \multicolumn{7}{|l|}{ Infection Sites } \\
\hline Lung & 1 & & & 1 & & \\
\hline Urinary tract & 0.63 & $0.54-0.73$ & $<0.001^{*}$ & 0.61 & $0.52-0.71$ & $<0.001^{*}$ \\
\hline Intestinal tract & 0.49 & $0.37-0.65$ & $<0.001^{*}$ & 0.48 & $0.33-0.69$ & $<0.001^{*}$ \\
\hline Skin soft-tissue & 0.50 & $0.35-0.72$ & $<0.001^{*}$ & 0.46 & $0.35-0.61$ & $<0.001^{*}$ \\
\hline \multicolumn{7}{|c|}{ Biochemical indexes } \\
\hline $\operatorname{WBC}\left(\times 10^{9} / \mathrm{L}\right)$ & 0.99 & $0.90-1.09$ & 0.54 & & & \\
\hline $\mathrm{HB}(\mathrm{g} / \mathrm{L})$ & 1.00 & $0.99-1.03$ & 0.27 & & & \\
\hline $\mathrm{CRP}(\mathrm{mg} / \mathrm{L})$ & 0.99 & $0.99-1.03$ & 0.59 & & & \\
\hline PCT(ng/ml) & 1.11 & $0.09-1.15$ & 0.60 & & & \\
\hline \multicolumn{7}{|c|}{ Medical history, n (\%) } \\
\hline Hypertension & 0.81 & $0.72-0.90$ & $<0.001^{*}$ & 0.74 & $0.66-0.84$ & $<0.001^{*}$ \\
\hline Diabetes & 0.87 & $0.75-1.01$ & 0.06 & & & \\
\hline
\end{tabular}

WBC white blood cell, $H B$ haemoglobin, $C R P C$-reactive protein, $P C T$ procalcitonin, $O R$ odds ratio, $C l$ confidence interval

*Significant differences $(P<0.05)$

Table 3 Analysis on Risk Factors Associated with Thrombocytopenia in Patients with Pulmonary Infection (N=11,941)

\begin{tabular}{|c|c|c|c|c|c|c|c|c|}
\hline \multirow[t]{2}{*}{ Variables } & \multirow{2}{*}{$\begin{array}{l}\text { Thrombocytopenia } \\
(n=1171)\end{array}$} & \multirow{2}{*}{$\begin{array}{l}\text { Normal platelet } \\
(n=10,770)\end{array}$} & \multicolumn{3}{|c|}{ Univariate Analysis } & \multicolumn{3}{|c|}{ Multivariate Analysis } \\
\hline & & & OR & $95 \% \mathrm{Cl}$ & $P$ value & OR & $95 \% \mathrm{Cl}$ & $P$ value \\
\hline Age, years (SD) & $57.79 \pm 24.06$ & $58.76 \pm 23.74$ & 0.99 & $0.99-1.00$ & 0.19 & & & \\
\hline Sex, female, n (\%) & $454(38.8)$ & $4356(40.4)$ & 0.93 & $0.82-1.06$ & 0.27 & & & \\
\hline \multicolumn{9}{|c|}{ Biochemical indexes } \\
\hline WBC $\left(\times 10^{9} / L\right)$ & $9.90 \pm 3.98$ & $9.96 \pm 4.08$ & 0.99 & $0.98-1.01$ & 0.63 & & & \\
\hline $\mathrm{HB}(\mathrm{g} / \mathrm{L})$ & $126.75 \pm 33.31$ & $127.81 \pm 33.49$ & 0.98 & $0.98-0.99$ & 0.30 & & & \\
\hline $\mathrm{CRP}(\mathrm{mg} / \mathrm{L})$ & $49.54 \pm 48.18$ & $51.23 \pm 49.29$ & 0.99 & $0.98-1.00$ & 0.26 & & & \\
\hline PCT (ng/ml) & $0.25 \pm 0.15$ & $0.31 \pm 0.10$ & 0.98 & $0.97-1.99$ & 0.87 & & & \\
\hline CPIS scores & $7.25 \pm 2.16$ & $7.00 \pm 2.99$ & 1.25 & $1.18-1.32$ & $<0.001^{*}$ & 1.24 & $1.17-1.31$ & $<0.001^{*}$ \\
\hline \multicolumn{9}{|c|}{ Medical history, n (\%) } \\
\hline Hypertension & $392(33.5)$ & $4385(40.7)$ & 0.73 & $0.65-0.83$ & $<0.001^{*}$ & 0.74 & $0.65-0.85$ & $<0.001^{*}$ \\
\hline Diabetes & $177(15.1)$ & 1798 (16.7) & 0.89 & $0.75-1.05$ & 0.17 & & & \\
\hline $\mathrm{RF}$ & $101(8.6)$ & $574(5.3)$ & 1.68 & $1.35-2.09$ & $<0.001^{*}$ & 1.59 & $1.27-1.98$ & $<0.001^{*}$ \\
\hline COPD & $78(6.7)$ & $519(4.8)$ & 1.24 & $0.91-1.68$ & 0.17 & & & \\
\hline
\end{tabular}

Date were presented as mean $\pm(\mathrm{SD})$ or $\mathrm{n}(\%)$

$W B C$ white blood cell, $H B$ haemoglobin, $C R P C$-reactive protein, $P C T$ procalcitonin, $C P I S$ clinical lung infection score, $R F$ respiratory failure, $C O P D$ chronic obstructive lung disease, $O R$ odds ratio, $C l$ confidence interval

*Significant differences $(P<0.05)$

hypoxic mice confirmed the speculation that low $\mathrm{PaO}_{2}$ could reduce MKs and impair the thrombocytopoiesis in lungs.

Although infection is known to cause thrombocytopenia [22-24], cohort studies associated with different organ infections have not been reported. In the present study, the incidence of thrombocytopenia in PIN patients showed a significant increase, which suggested that the lungs could affect the physiological behavior of platelets in a particular way. Based on the conclusion that there were no associations between bacterial species and the incidence of thrombocytopenia in infectious diseases 
Table 4 Analysis on risk factors associated with thrombocytopenia in pulmonary infection patients accompanying by respiratory failure $(\mathrm{N}=675)$

\begin{tabular}{|c|c|c|c|c|c|c|c|c|}
\hline \multirow[t]{2}{*}{ Variables } & \multirow{2}{*}{$\begin{array}{l}\text { Thrombocytopenia } \\
(\mathrm{n}=101)\end{array}$} & \multirow[t]{2}{*}{ Normal platelet $(n=574)$} & \multicolumn{3}{|c|}{ Univariate analysis } & \multicolumn{3}{|c|}{ Multivariate analysis } \\
\hline & & & OR & $95 \% \mathrm{Cl}$ & $P$ value & OR & $95 \% \mathrm{Cl}$ & $P$ value \\
\hline Age, years (SD) & $58.92 \pm 25.00$ & $58.25 \pm 23.45$ & 1.00 & $0.99-1.01$ & 0.79 & & & \\
\hline Sex, female, n (\%) & $34(33.7)$ & $170(29.6)$ & $1 \cdot 21$ & $0.77-1.89$ & 0.41 & & & \\
\hline \multicolumn{9}{|l|}{ Biochemical indexes } \\
\hline WBC $\left(\times 10^{9} / L\right)$ & $9.48 \pm 3.84$ & $9.94 \pm 4.01$ & 0.97 & $0.92-1.02$ & 0.28 & & & \\
\hline $\mathrm{HB}(\mathrm{g} / \mathrm{L})$ & $126.39 \pm 33.65$ & $129.61 \pm 33.32$ & 0.09 & $0.99-1.01$ & 0.37 & & & \\
\hline CRP (mg/L) & $45.39 \pm 44.97$ & $49.94 \pm 48.43$ & 0.99 & $0.99-1.00$ & 0.38 & & & \\
\hline PCT (ng/ml) & $1.5 \pm 1.2$ & $1.6 \pm 1.1$ & 0.99 & $0.99-1.01$ & 0.56 & & & \\
\hline APACHEll scores & $13.3 \pm 3.9$ & $12.3 \pm 3.5$ & 1.09 & $1.02-1.15$ & $0.007^{*}$ & 1.06 & $1.01-1.13$ & $0.03^{*}$ \\
\hline \multicolumn{9}{|l|}{$A B G A$} \\
\hline $\mathrm{PH}$ & $7.39 \pm 0.2$ & $7.38 \pm 0.2$ & 1.08 & $0.30-3.90$ & 0.90 & & & \\
\hline $\mathrm{PaO}_{2}(\mathrm{mmHg})$ & $46.2 \pm 7.5$ & $52.8 \pm 5.8$ & 0.88 & $0.85-0.91$ & $<0.001^{*}$ & 0.88 & $0.85-0.92$ & $<0.001^{*}$ \\
\hline $\mathrm{PaCO}_{2}(\mathrm{mmHg})$ & $39.5 \pm 16.1$ & $38.7 \pm 16.8$ & 1.00 & $0.99-1.02$ & 0.64 & & & \\
\hline \multicolumn{9}{|c|}{ Medical history, $n(\%)$} \\
\hline Hypertension & $34(33.7)$ & $255(44.4)$ & 0.64 & $0.41-0.99$ & $0.046^{*}$ & 0.65 & $0.41-1.05$ & 0.08 \\
\hline Diabetes & $16(15.8)$ & $120(21.0)$ & 0.71 & $0.40-1.26$ & 0.24 & & & \\
\hline COPD & $34(33.7)$ & $128(22.3)$ & 2.35 & $1.22-4.53$ & $0.01^{*}$ & 2.40 & $1.22-4.76$ & $0.01^{*}$ \\
\hline
\end{tabular}

Date were presented as mean $\pm(\mathrm{SD})$ or $\mathrm{n}(\%)$

WBC white blood cell, HB haemoglobin, CRP C-reactive protein, PCT procalcitonin, APACHE Il scores Acute Physiology and Chronic Health Evaluation, ABGA arterial blood gas analysis, $\mathrm{PaO}_{2}$ oxygen partial pressure, $\mathrm{PaCO}_{2}$ partial pressure of carbon dioxide, $\mathrm{COPD}$ chronic obstructive lung disease, $\mathrm{OR}$ odds ratio, $\mathrm{Cl}$ confidence interval

*Significant differences $(P<0.05)$

[23], we speculate that lower $\mathrm{PaO}_{2}$ might cause pulmonary thrombocytopenia.

The correlation between low $\mathrm{PaO}_{2}$ and thrombocytopenia had been previously described. A clinical observation showed that thrombocytopenia occurred in $31 \%$ of neonates with asphyxia versus $5 \%$ of matched controls without asphyxia [25]. Another study found that thrombocytopenia was a predictive factor for the progression of pneumonia to RF [26]. We confirmed in clinical cases that low $\mathrm{PaO}_{2}$ was a key risk factor for thrombocytopenia through a relatively large sample of PIN patients for the first time. Severity of disease was associated with the incidence of thrombocytopenia [22, 24]. There was a relatively high incidence of thrombocytopenia ranging from 20 to $50 \%$ in critical patients [27]. Both the CPIS and the APACHE II score were positively associated with the risk of thrombocytopenia. It was worth mentioning that low $\mathrm{PaO}_{2}$ was an independent risk factor for thrombocytopenia after adjusting for the APACHE II score, which makes the results more convincing.

The influence of hypoxia on bone marrow MKs is well described. Chronic hypoxia impair bone marrow MKs [28] and inhibit the differentiation of bone marrow MKs[29], or the erythroid system and the MK system share a common precursor in the bone marrow, and there is competition between erythroid and MK differentiation upon exposure to a hypoxic environment [30]. However, the effect of hypoxia on pulmonary thrombocytopoiesis has not been investigated as the lung is another important site of platelet biogenesis. We constructed hypoxic mouse models and found that low $\mathrm{PaO}_{2}$ caused thrombocytopenia. P-selectin, an indicator of platelet activation, showed no significant difference between hypoxic and normoxic mice, which indicated that thrombocytopenia was not attributed to platelet activation. Researchers have paid close attention to the process of platelet generation in lungs $[3,19]$. There are abundant MKs in the pulmonary arterial blood but only a few MKs in the pulmonary venous blood under normal conditions [21], but thrombocytopenia occurs in patients with congenital heart diseases because a right-to-left shunt bypasses the lung where thrombocytopoiesis occurs [31]. A large number of MKs dynamically circulate through the lungs, where they release platelets [19]. Consistent with these findings, we observed a large number of CD41-positive MKs in the mouse lungs and found that the PLT $_{\text {post }}$ was higher than the PLT $_{\text {pre, }}$ indicating that the mouse lungs indeed were a site of platelet production. Interestingly, we found that hypoxia could reduce lung MKs and impair efficacy of thrombocytopoiesis in lung. 
a
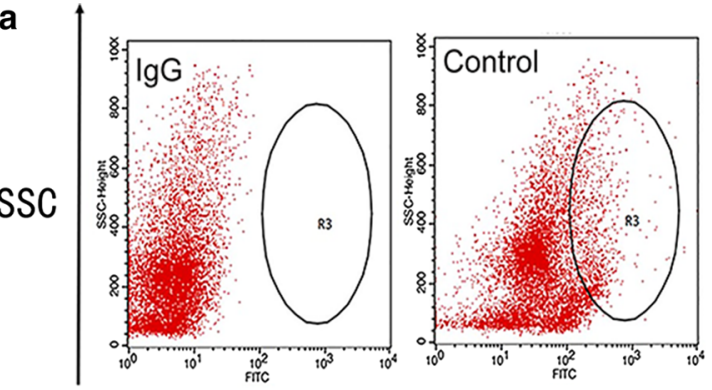

C<smiles>C1CCCCC1</smiles>
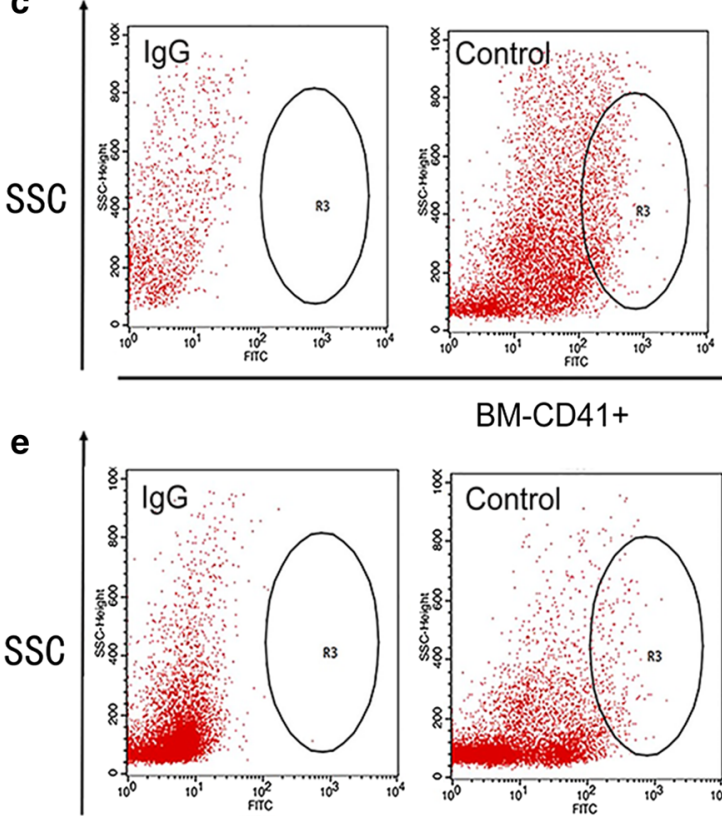

Lung-CD41+

BM-CD41+
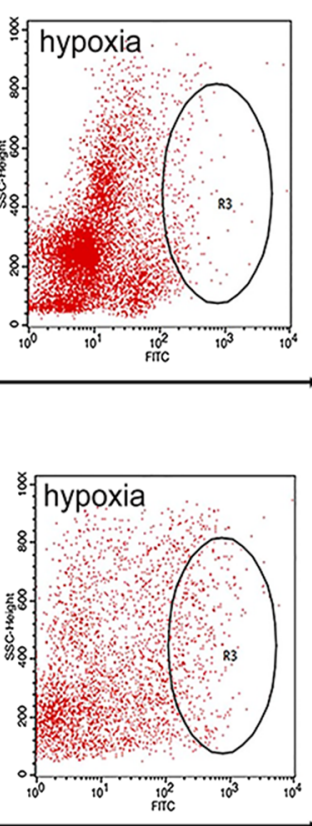

$\sqrt[8]{\text { Control }}$

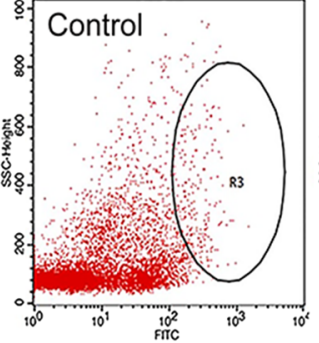

Spleen-CD41+

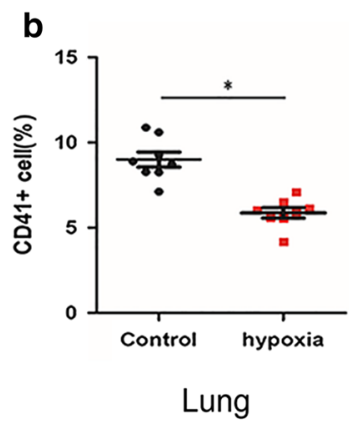

d

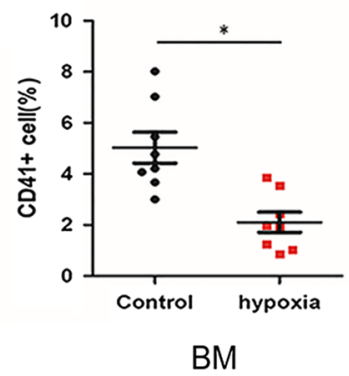

f
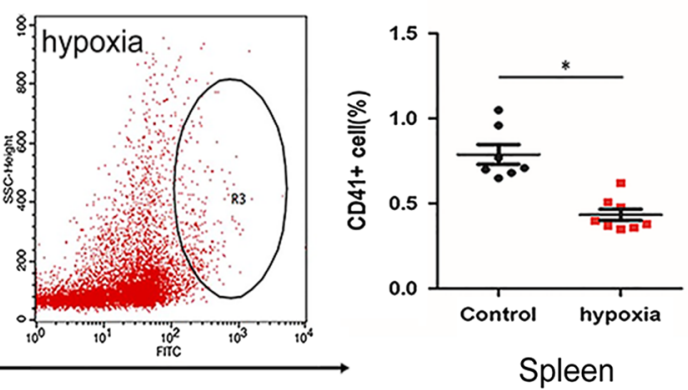

Fig. 2 Hypoxia reduce the megakaryocytes in lung and other hematopoietic tissues (flow cytometry). Area for R3 define the amount of positive cells (determined bythe lgG-control isotypes). a Representative dot-plots of the staining of cell suspensions from the lung; $\mathbf{b}$ Comparation of the proportion of megakaryocytes in lungs between the two groups. Each point represents the mean adjusted value of 3 replicates for each individual mouse $(n=8)$. $P$ values were calculated using the Mann-Whitney $U$ test. ${ }^{*} P<0.05$; c Representative dot-plots of the staining of cell suspensions from the bone marrow; $\mathbf{d}$ Comparation of the proportion of megakaryocytes in the BW between the two groups. Each point represents the mean adjusted value of 3 replicates for each individual mouse $(n=8)$. $P$ values were calculated using the t test. ${ }^{*} P<0.05$; e Representative dot-plots of the staining of cell suspensions from the spleen; $\mathbf{f}$ Comparation of the proportion of megakaryocytes in the spleen between the two groups ( $n=8$ ). $P$ values were calculated using the Mann-Whitney $U$ test. ${ }^{*} P<0.05$

The conclusion from the present study could be helpful for patients with respiratory diseases. We discovered an interesting relationship between thrombocytopenia and pulmonary infections, as well as the corresponding hypoxemia. We found that megakaryocytes decreased in lung of hypoxia mice who produce only few platelets, suggesting that hypoxemia could result in reduced platelets and increased the risk of bleeding. Hypoxemia was common in patients suffering from COPD or bronchiectasis, or living in high altitude, so the clinicians should be aware of the risk of pulmonary thrombocytopenia. According to these reasons, we suggest that patients with severe lung diseases, especially those with hypoxemia complications should dynamically monitor the platelet and take circumspect application of antiplatelet drugs.

It is important to note that there are several limitations in our study. First, a larger-scale, multicenter, prospective 


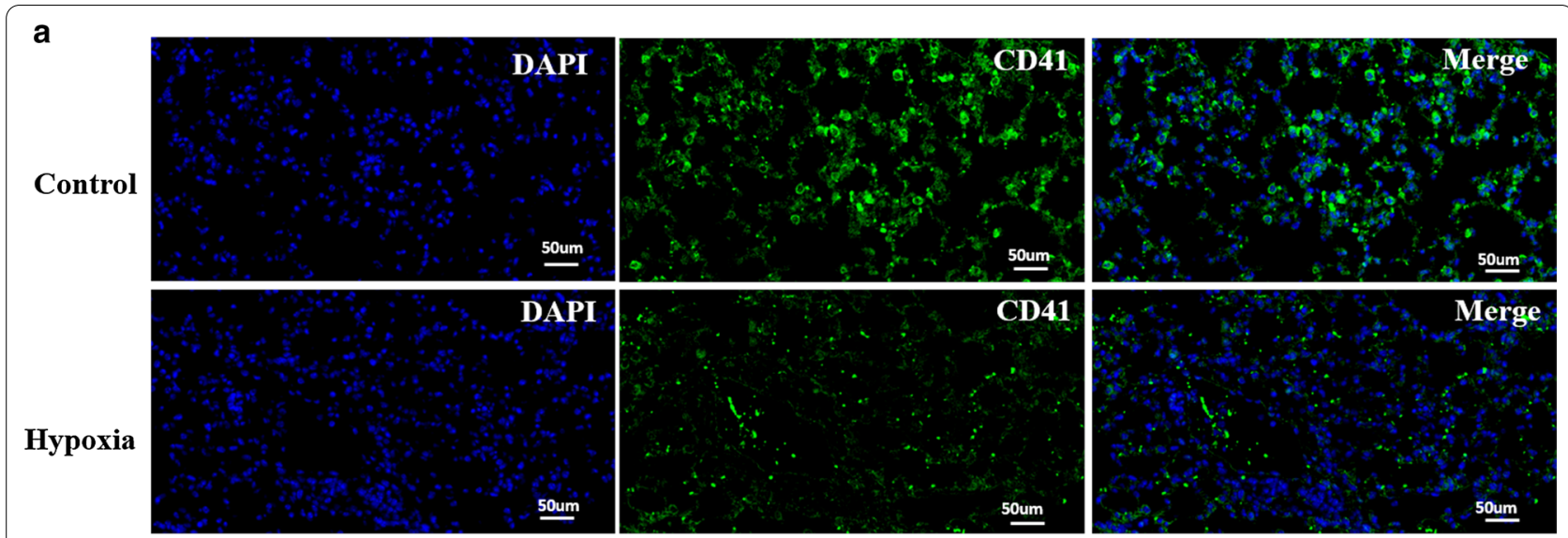

b

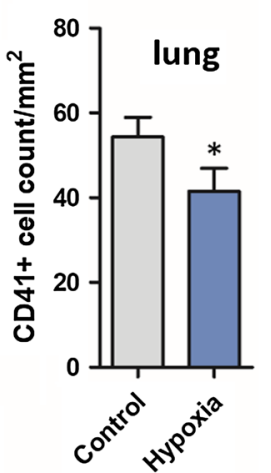

Fig. 3 Hypoxia reduce the megakaryocytes in lung(immunofluorescence). a In representative images from sections of the lung, MKs (green, CD41) and nuclei (blue, DAPI) were showed. Scale: 50um; $\mathbf{b}$ Comparation of the megakaryocyte number between the two group. The y axis shows the number of CD41-positive cells per square millimeter. The data in the graphs are the means \pm s.e.m. $(n=8), p$ values were calculated with the two-tailed Student t-test. ${ }^{*} P<0.05$

investigation based on the relationship between thrombocytopenia and respiratory failure is needed to provide more convinced evidence. Second, the detailed molecular mechanisms underlying the process of platelet generation in lungs and how low $\mathrm{PaO}_{2}$ affected this process were not illuminated. In spite of these limitations, we believe that our results are the first to provide the correlation between lung diseases and thrombocytopenia with data from both clinical studies and mouse models. We anticipate that future studies will focus on identification of mechanisms underlying pulmonary thrombocytopenia through mouse models of lung injury.

\section{Conclusions}

PIN relatively easily results in thrombocytopenia and thrombocytopenia induced by low $\mathrm{PaO}_{2}$ might be associated with impaired thrombopoiesis in lungs.

\section{Supplementary information}

The online version contains supplementary material available at https://doi. org/10.1186/s12890-020-01381-7.

Additional file 1. Pathogen does not affect the distribution of oxygen partial pressure in pulmonary infection patients accompanying by respiratory failure.

Additional file 2. Analysis on Pathogens Associated with Thrombocytopenia in Pulmonary Infection Patients accompanying by Respiratory Failure.

Additional file 3. Hypoxia reduce the megakaryocytes in marrow (immunofluorescence).

Additional file 4. Hypoxia reduce the megakaryocytes in spleen (immunofluorescence).

\section{Abbreviations}

PIN: Pulmonary Infection; UTI: Urinary Tract Infection; MKs: Megakaryocytes; RF: Respiratory Failure; COPD: Chronic Obstructive Pulmonary Disease; $\mathrm{PaO}_{2}$ : Oxygen Partial Pressure; ICD-10: International classification of diseases code-10; UTI: Urinary tract infection; ITI: Intestinal tract infection; CPIS: Clinical pulmonary infection score; APACHE II: Acute Physiology And Chronic Health Evaluation II; PLTs: Blood platelets in angular vein; PLT post: Blood platelets in left 
ventricle; $\mathrm{PLT}_{\text {pre: }}$ : Blood platelets in right ventricle; $\triangle \mathrm{PLT}$ post-pre: The difference between the PLT post and the $\mathrm{PLT}_{\text {pre: }}$

\section{Acknowledgements}

Not applicable.

\section{Authors' contributions}

Prof. KH conceived and designed the study. LW and NG completed the animal experiment. NG, QMX, ZX, JH and RW performed data collection and analysis. WW calculated the CPIS and APACHE II scores. NG and LW wrote the paper. Prof. KH reviewed and edited manuscript. All authors read and approved the final manuscript.

\section{Funding}

This work was supported by National Natural Science Foundation of China (No.81530013), National Key R\&D Program of China (No.2017YFC1307804) for Prof. Kui Hong, National Natural Science Foundation of China (No.81600243). The funders had no role in the design of the study and collection, analysis, and interpretation of data and in writing the manuscript.

\section{Availability of data and materials}

All data generated or analyzed and material used during this study are available from the corresponding author on reasonable request.

\section{Ethics approval and consent to participate}

The study procedures were approved by both the Medical Ethics Committee and the Animal Care and Use Committee of the Second Affiliated Hospital of Nanchang University. All patients were asked to sign an informed consent form authorizing inclusion of their clinical data in the study database.

\section{Consent to publication}

Not applicable.

\section{Competing interests}

The authors declare that there is no competing interests to declare.

\section{Author details}

${ }^{1}$ Department of Cardiovascular Medicine and Jiangxi Key Laboratory of Molecular Medicine, The Second Affiliated Hospital of Nanchang University, Nanchang 330006, Jiangxi, China. ${ }^{2}$ Department of Hematology Medicine, The Second Affiliated Hospital of Nanchang University, Nanchang, China. ${ }^{3}$ Molecular Medicine of Jiangxi Key Laboratory, The Second Affiliated Hospital of Nanchang University, Nanchang, China. ${ }^{4}$ Department of Respiratory Medicine, The Second Affiliated Hospital of Nanchang University, Nanchang, China. ${ }^{5}$ Department of Genetic Medicine, The Second Affiliated Hospital of Nanchang University, Nanchang, China.

Received: 13 June 2020 Accepted: 15 December 2020

Published online: 06 January 2021

\section{References}

1. Versteeg HH, Heemskerk JW, Levi M, Reitsma PH. New fundamentals in hemostasis. PHYSIOL REV. 2013;93(1):327-58.

2. Machlus KR, Italiano JJ. The incredible journey: from megakaryocyte development to platelet formation. J CELL BIOL. 2013:201(6):785-96.

3. Weyrich AS, Zimmerman GA. Platelets in lung biology. Annu Rev Physiol. 2013;75:569-91.

4. Levine RF, Eldor A, Shoff PK, Kirwin S, Tenza D, Cramer EM. Circulating megakaryocytes: delivery of large numbers of intact, mature megakaryocytes to the lungs. Eur J Haematol. 1993;51(4):233-46.

5. Gouveia C, Evangelista V, Almeida R, Baptista AM. Immune thrombocytopenia associated with mycoplasma pneumoniae infection. Eur J Case Rep Intern Med. 2018;5(3):817.

6. Valdivia-Arenas MA, Sood N. A 77-year-old farmer with respiratory failure and thrombocytopenia. Chest. 2006;129(5):1378-81.

7. Fawzy A, Anderson JA, Cowans NJ, Crim C, Wise R, Yates JC, Hanse NN. Association of platelet count with all-cause mortality and risk of cardiovascular and respiratory morbidity in stable COPD. Respir Res. 2019;20(1):86
8. WHO: The ICD-10 classification of mental and behavioural disorders: clinical descriptions and diagnostic guidelines. World Health Organization 1992.

9. Myriam Arévalo-Herrera DAFA: Guidance for Industry. Toxicity Grading Scale for Healthy Adult and Adolescent Volunteers Enrolled in Preventive Vaccine Clinical Trials. In.; 2005.

10. Berg AS, Inchley CS, Fjaerli HO, Leegaard TM, Lindbaek M, Nakstad B. Clinical features and inflammatory markers in pediatric pneumonia: a prospective study. Eur J Pediatr. 2017;176(5):629-38.

11. Knaus WA, Draper EA, Wagner DP, Zimmerman JE. APACHE II: a severity of disease classification system. Crit Care Med. 1985;13(10):818-29.

12. Ochiai T, Yasuda H, Araki M, Misawa K, Morishita S, Nudejima M, Hironaka Y, Shirane S, Edahiro Y, Gotoh A, et al. The 2014 BCSH criteria and the 2016 WHO criteria for essential thrombocythemia: a comparison in a largescale cohort. Eur J Haematol. 2018;100(6):544-9.

13. Nakanishi K, Tajima F, Osada H, Kato T, Miyazaki H, Kawai T, Torikata C, Suga T, Takishima K, Aurues T, et al. Thrombopoietin expression in normal and hypobaric hypoxia-induced thrombocytopenic rats. Lab Invest. 1999;79(6):679-88.

14. Singer BD, Mock JR, D'Alessio FR, Aggarwal NR, Mandke P, Johnston L, Damarla M. Flow-cytometric method for simultaneous analysis of mouse lung epithelial, endothelial, and hematopoietic lineage cells. Am J Physiol Lung Cell Mol Physiol. 2016;310(9):L796-801.

15. Leelatian N, Doxie DB, Greenplate AR, Mobley BC, Lehman JM, Sinnaeve J, Kauffmann RM, Werkhaven JA, Mistry AM, Weaver KD, et al. Single cell analysis of human tissues and solid tumors with mass cytometry. Cytometry B Clin Cytom. 2017;92(1):68-78.

16. Rowley JW, Oler AJ, Tolley ND, Hunter BN, Low EN, Nix DA, Yost CC, Zimmerman GA, Weyrich AS. Genome-wide RNA-seq analysis of human and mouse platelet transcriptomes. Blood. 2011;118(14):e101-11.

17. Fu W, Wang J, Jiang $\mathrm{H}, \mathrm{Hu} X$. Myocardial infarction induces bone marrow megakaryocyte proliferation, maturation and platelet production. Biochem Biophys Res Commun. 2019;510(3):456-61.

18. Aschoff $L$. Ueber capill ire Embolie yon riesenkernhaltigen Zellen. Arch Pathol Anat Phys. 1893;134(1):11-4.

19. Lefrancais E, Ortiz-Munoz G, Caudrillier A, Mallavia B, Liu F, Sayah DM, Thornton EE, Headley MB, David T, Coughlin SR, et al. The lung is a site of platelet biogenesis and a reservoir for haematopoietic progenitors. Nature. 2017;544(7648):105-9.

20. Howell WH, Donahue DD. the production of blood platelets in lungs. J Exp Med. 1937;65(2):177-203.

21. Dejima H, Nakanishi H, Kuroda H, Yoshimura M, Sakakura N, Ueda N, Ohta Y, Tanaka R, Mori S, Yoshida T, et al. Detection of abundant megakaryocytes in pulmonary artery blood in lung cancer patients using a microfluidic platform. Lung Cancer. 2018;125:128-35.

22. Stasi R, Willis F, Shannon MS, Gordon-Smith EC. Infectious causes of chronic immune thrombocytopenia. Hematol Oncol Clin North Am. 2009;23(6):1275-97.

23. Johansson $D$, Rasmussen $M$, Inghammar M. Thrombocytopenia in bacteraemia and association with bacterial species. Epidemiol Infect. 2018;146(10):1312-7.

24. Parikh F. Infections and thrombocytopenia. J Assoc Phys India. 2016:64(2):11-2.

25. Christensen RD, Baer VL, Yaish HM. Thrombocytopenia in late preterm and term neonates after perinatal asphyxia. Transfusion. 2015;55(1):187-96.

26. Ko JH, Park GE, Lee JY, Lee JY, Cho SY, Ha YE, Kang Cl, Kang JM, Kim YJ, Huh HJ, et al. Predictive factors for pneumonia development and progression to respiratory failure in MERS-CoV infected patients. J Infect. 2016;73(5):468-75.

27. Akca S, Haji-Michael P, de Mendonca A, Suter P, Levi M, Vincent JL. Time course of platelet counts in critically ill patients. Crit Care Med. 2002:30(4):753-6.

28. Rolovic Z, Basara N, Biljanovic-Paunovic L, Stojanovic N, Suvajdzic N, Pavlovic-Kentera V. Megakaryocytopoiesis in experimentally induced chronic normobaric hypoxia. Exp Hematol. 1990;18(3):190-4.

29. Lebedeva EV, Yushkov BG, Chereshnev VA. Megakaryocytopoiesis under hypoxic conditions. Bull Exp Biol Med. 2003;136(6):554-6.

30. McDonald TP, Cullen WC, Cottrell M, Clift R. Effects of hypoxia on the small acetylcholinesterase-positive megakaryocyte precursor in bone marrow of mice. Proc Soc Exp Biol Med. 1986;183(1):114-7. 
31. Lill MC, Perloff JK, Child JS. Pathogenesis of thrombocytopenia in cyanotic congenital heart disease. Am J Cardiol. 2006;98(2):254-8.

\section{Publisher's Note}

Springer Nature remains neutral with regard to jurisdictional claims in published maps and institutional affiliations.

Ready to submit your research? Choose BMC and benefit from:

- fast, convenient online submission

- thorough peer review by experienced researchers in your field

- rapid publication on acceptance

- support for research data, including large and complex data types

- gold Open Access which fosters wider collaboration and increased citations

- maximum visibility for your research: over 100M website views per year

At $\mathrm{BMC}$, research is always in progress.

Learn more biomedcentral.com/submissions 